\title{
GENERALIZATIONS OF SOME CLASSICAL RESULTS UNDER MVBV CONDITION
}

\author{
M. Z. WANG AND Y. ZHAO
}

Abstract. The present paper applies MVBV condition to generalize certain classical results for asymptotic relation for a certain trigonometric series, and for an important trigonometric inequality. The new results contain all previous corresponding results. By citing a theorem in [7], we also show that MVBV condition is the ultimate generalization for the trigonometric inequality.

Mathematics subject classification (2000): 42A20 42A32. inequality.

Keywords and phrases: monotonicity, mean value, bounded variation, asymptotic relation, trigonometric

\section{REFERENCES}

[1] P. B. BorweIn AND S. P. ZHOU, Rational approximation in Lipschitz and Zygmund classes, Constr. Approx. 8(1992), 381-399.

[2] R. J. LE AND S. P. ZHOU, A new condition for the uniform convergence of certain trigonometric series, Acta Math. Hungar. 108(2005), 161-169.

[3] R. J. LE AND S. P. ZHoU, A generalization of an important trigonometric inequality, J. Anal. Appl. 3(2005), 163-168.

[4] L. LEINDLER, On the uniform convergence and boundedness of a certain class of sine series, Anal. Math. 27(2001), 279-285.

[5] T. F. XIE AND S. P. ZHou, On certain trigonometric series, Analysis 14(1994), 227-237.

[6] S. P. ZHOU AND R. J. LE, A new condition for certain trigonometric series, Anal. Theory Appl. 22(2006), $1-8$.

[7] S. P. ZHOU, P. ZHOU AND D. S. YU, Ultimate generalization to monotonicity for uniform convergence of trigonometric series, arXiv: math.CA/0611805 v1 27 Nov 2006.

[8] L. LEINDLER, A note on the uniform convergence and boundedness of a new class of sine series, Anal. Math. 31(2005),269-275.

[9] L. LeINDLER, A new extension of monotone sequences and its applications, J. Ineq. Pure Appl. Math. (Electronic), 7:1(2006), Article 39.

[10] L. LEINDLER, Necessary and sufficient conditions for uniform convergence and boundedness of a general class of sine series, Austral. J. Math. Anal. Appl. (Electronic), 4:1(2007), Article 10. 